\title{
HAKEKAT ARSITEKTUR KAMPUNG KOTA DALAM KONTEKS FILOSOFIS
}

\author{
Indah Yuliasari ${ }^{1}$ \\ ${ }^{1}$ Universitas Indraprasta PGRI, Program Studi Arsitektur \\ yuliasari.wibowo@gmail.com
}

\begin{abstract}
The space that forms the urban village space. the spatial planning pattern of the village from the beginning of the establishment of the urban village starts from history, philosophy, concepts, factors that affect space, and cultural traditions that can help in maintaining the authenticity of the urban kampung space. Kampung kota is not a built environment that was built in a short time but was formed in a long time and is an accumulation of each stage of previous development. Research uses descriptive qualitative methods by describing things related to the physical elements in the village. The study also used a qualitative explanation method which was carried out by describing the existing phenomena in detail, also conducted interview notes and conducted document analysis. In order to anticipate that the tendency to reveal the phenomenon of city identity like that does not continue, it is necessary to study and trace the identity of a city based on the order and function of city life in a more integrated manner which is an accumulation of the socio-cultural values of city residents as the spirit and identity of the city., as well as the physical elements of the environment as the container. Historical aspects and the introduction of the "image" captured by city residents are important in the meaning of city identity or regional image. Rediscovery of the city's identity as part of community life in an effort to meet the needs of village residents and improve the quality of its environment can be carried out in a sustainable manner on the basis of indigenous knowledge. Architecturally, this kinship value system is related to the concept of boundaries and territories, spatial proximity, communal space, and topological patterns. Keywords: urban village, architectural perspective
\end{abstract}

\begin{abstract}
Abstrak. Ruang yang membentuk ruang kampung kota. pola penataan ruang kampung dari awal berdirinya kampung kota dimulai dari sejarah, filosofi, konsep, faktor-faktor yang mempengaruhi ruang, dan tradisi budaya yang dapat membantu dalam menjaga keaslian ruang kampung kota.Kampung kota bukanlah lingkungan binaan yang dibangun dalam waktu singkat tetapi dibentuk dalam waktu yang panjang dan merupakan akumulasi setiap tahap perkembangan sebelumnya Penelitian menggunakan metode kualitatif deskriptif dengan menjabarkan hal yang terkait dengan elemen fisik yang ada dikampung. Penelitian juga menggunakan metode eksplanasi kualitatif yang dilakukan dengan mendeskripsikan fenomena yang ada dengan detail, juga dilakukan catatan wawancara dan melakukan analisis dokumen. Untuk mengantisipasi agar kecenderungan pengungkapan fenomena identitas kota seperti itu tidak berlanjut, perlu kiranya dipelajari dan ditelusuri identitas suatu kota berdasarkan tatanan dan fungsi kehidupan kota secara lebih terintegrasi yang di dalamnya merupakan akumulasi dari nilai-nilai sosio-kultural warga kota sebagai ruh dan jati diri kota, serta elemen-elemen fisik lingkungan sebagai wadahnya. Aspek historis dan pengenalan "image" yang diitangkap oleh warga kota menjadi penting dalam pemaknaan identitas kota atau citra kawasan. Penemuan kembali jati diri kota sebagai bagian hidup masyarakat dalam upaya pemenuhan kebutuhan warga kampung dan peningkatan kualitas lingkungannya dapat dilakukan secara berkelanjutan (sustainable) atas dasar kearifan-kearifan tradisional (indigenous knowledge). Secara arsitektural tata nilai kekerabatan ini berkaitan dengan konsep batas dan teritori, kedekatan tempat tinggal (spatial proximity), ruang komunal, serta pola topologi.
\end{abstract}

Kata Kunci : kampung kota, perspektif arsitektur

\section{PENDAHULUAN}

Ruang arsitektur kampung kota terbentuk karena filosofi dari lokasinya (di dalam maupun di luar pemukiman). Ruang ini dapat berupa bangunan, jalan, hulu saluran air, area dekat pohon dan lainlain. Ruang yang membentuk ruang kampung kota. pola penataan ruang kampung dari awal berdirinya kampung kota dimulai dari sejarah, filosofi, konsep, faktor-faktor yang mempengaruhi ruang, dan tradisi budaya yang dapat membantu dalam menjaga keaslian ruang kampung kota. Lokalitas yang terkandung pada 
tatanan kampung kota akan memberi karakter bagi pembentukan semangat urbanisme baru yang sesuai dengan karakter masyarakat, bersumber pada ideologi bermukim yang berkelanjutan. Beranjak dari paradigma perencanaan kota, kampung kota sebenarnya dapat menjadi awal dimulainya paradigma baru perencanaan kota dalam mewujudkan kota yang lebih baik.

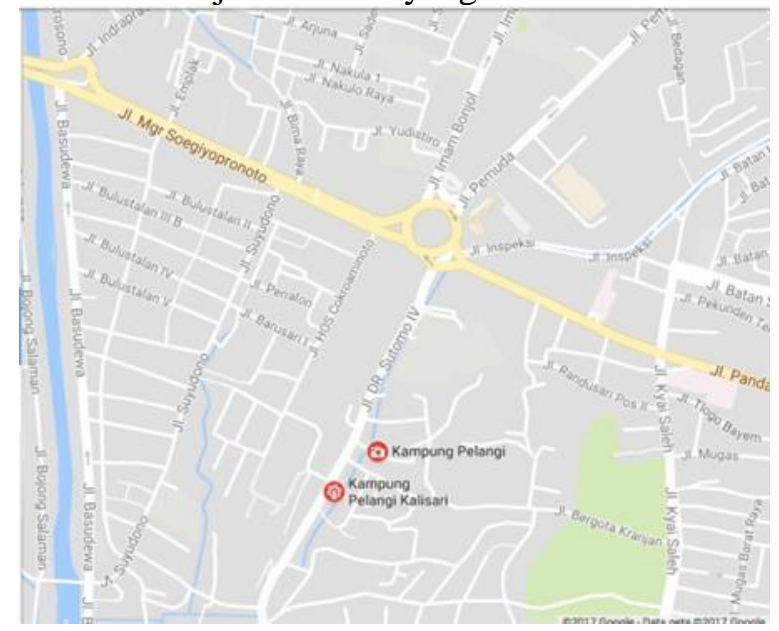

Gambar 1 Peta lokasi Kampung Kalisari Semarang

Kampung kota dapat dikenal bila diketahui dan dipahami secara baik dan menyeluruh melalui penelusuran ciri-ciri, tanda-tanda atau jati diri, baik elemen fisik (tangible) maupun psikis (intangible), dengan senantiasa memperhatikan kondisi faktual tatanan dan fungsi kehidupan kota, nilai-nilai historis serta nilai-nilai lokal setempat sebagai keunikan dan karakteristik tersendiri, tanpa mengabaikan apresiasi masyarakat dan lingkungannya. Hal ini lebih disebabkan oleh beberapa fenomena, antara lain:terjadinya peningkatan percepatan perubahan ruangruang kota secara sistematis dan sangat pragmatis mengakibatkan menurunnya kualitas lingkungan kota terjadinya generalisasi dan keseragaman bentuk perkembangan dan visual kota, sehingga kota tersebut semakin asing bagi masyarakat terutama dalam mengenali dan menggali potensi jati diri untuk pemenuhan kebutuhan hidupnya dan pembangunan kota lebih dititiberatkan pada pertimbangan aspek fisik dan ekonomi serta cenderung mengabaikan nilai-nilai sosial budaya lokal dan historis kota.

Setiap kota memiliki jati diri atau cirinya masing-masing antara masyarakat dan lingkungan (fisik) kotanya. Kebudayaan masyarakatnyalah yang menjadi jiwa dan karakter kota itu, serta aspek lingkungan (fisik) akan menjadi raganya. Keduanya bagaikan sekeping mata uang dengan dua sisinya. Apabila karakter sebuah kota kuat, maka masyarakat pendatang biasanya akan lebur dalam jati diri kota yang dituju.

Pengaruh dari luar akan sulit masuk, bahkan kota akan mempengaruhi daerah sekitarnya. Kemampuan kota mempertahankan karakter dan identitasnya, bahkan mempengaruhi daerah dan kota sekitarnya disebut memiliki local genius. Oleh karena itu, membangun kota (city) pada dasarnya membangun (jiwa) masyarakatnya. Apabila jiwa masyarakatnya rapuh maka kota itu lambat laun akan rapuh pula dan demikian pula sebaliknya (Hariyono, 2007). Timbulnya kerisauan perihal bagaimana mengenal dan memahami identitas siapa dan apa kebutuhannya, berapa besar dan bagaimana memenuhi kebutuhan tersebut, serta berusaha menjaga dan memeliharanya secara baik dan berkesinambungan sesuai ciri-ciri atau jati diri yang dimilkinya. Demikian pula halnya dengan sebuah kota, untuk dapat memelihara dan memahami kebutuhan warga dan lingkungannya maka kota tersebut harus dapat dikenal dengan baik dan menyeluruh (comprehensive), sehingga kebutuhan warga kota dan kelestarian lingkungannya dapat dipenuhi dan dipelihara secara berkelanjutan (sustainable).

Perkembangan suatu kota tidak akan pernah lepas dari identitasnya, untuk itu amatlah penting sebagai paradigma kota itu sendiri. Tentunya jika berkunjung kesuatu tempat atau kota pastinya akan mencari apa yang menjadi ciri khas dari tempat yang dikunjungi. Kota harus bisa memberikan kenyamanan bagi yang ingin tinggal ataupun yang datang dengan tujuan mencari nafkah atau sekedar berwisata. Kota harus bisa memberikan apa yang dibutuhkan oleh warganya (citizen) dan juga dapat memberikan keramahan bagi siapapun, termasuk lingkungannya.

Kampung kota dan permukiman yaitu aspek fisik yang memiliki nilai dan norma di dalamnya serta dipengaruhi oleh faktor sosial budaya. Karakteristik sifat-sifat dasar lingkungan alam telah mempengaruhi manusia dari masa awal dengan berbagai cara. Lingkungan akan mempengaruhi manusia sewaktu mendirikan sebuah kampung atau permukiman.Rumah sebagai hasil bentukan arsitektur mencakup dua dimensi yaitu spasial dan sosial budaya masyarakat. Mengacu pada terminologi "genre de vie" yang di dalamnya mencakup kultural, spiritual dan aspek sosial, "Houses and setlements are the physical expression (sosio-culture) of the genre de vie (basic need and familly), and this constitute their simbolic nature (symbolic and cosmic)." (Rapoport, hal. 47 House Form and 
Culture. 1969). Terjemahanya Rumah dan permukiman adalah ekspresi (sosial-budaya) dari kebutuhan yang sangat mendasar dan ini merupakan wujud filosofis (simbolis dari kosmologis)

\section{Fenomena Kampung Kota}

Kampung Kota dalam kamus tata ruang merupakan bagian dari kota,terdiri atas kelompok perumahan, jumlah penduduk yang tinggi, kurang sarana dan prasarana, tidak terdapat luasan tertentu, dapat lebih besar dari satu kelurahan serta mengandung arti perumahan. yang dibangun secara tidak formal. Perumahan inilah yang disebut sebagai "kampung kota" atau perumahan yang seperti kampung di pedesaan, namun berada di wilayah perkotaan.

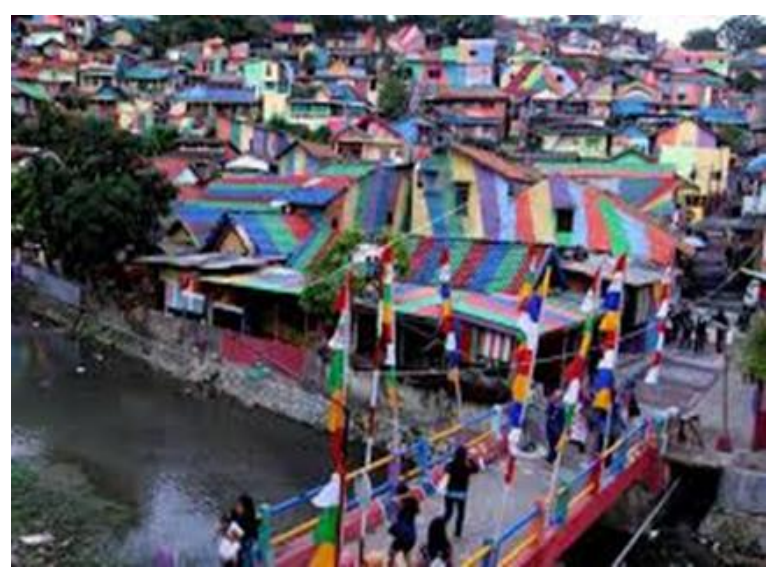

Gambar 2 Kampung kota Kalisari Semarang

Kampung kota biasanya identik dengan ketidakteraturan, ketidakseragaman, dan mungkin ketidakamanan serta bahkan ketidaksehatan. Hal ini disebabkan oleh bentuk rumah yang tidak teratur, lebar gang yang sempit ataupun kurangnya sarana dan prasarana di dalam lingkungannya (Kristiani, 2013). Kampung di dalam kota memiliki karakteristik tersendiri, yaitu kehidupan sebuah desa masih terdapat di dalamnya, yang masih nampak pada sistem sosial dan budaya yang mengikat. Akibatnya, keberadaan kampung ini mau tidak mau harus menjadi perhatian dan bagian dari kehidupan perkotaan, termasuk dalam proses perencanaan dan penataan kota.

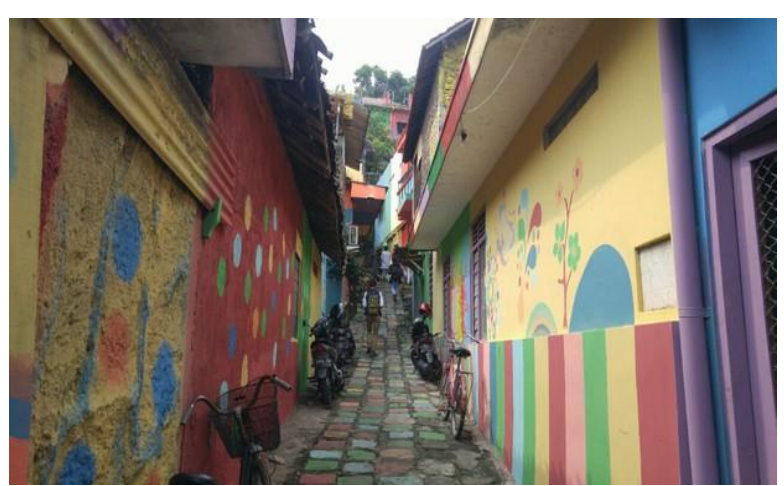

Gambar 3 Jalan dikampung kota Kalisari semarang

\section{METODOLOGI}

Metode Penelitian menggunakan metode kualitatif deskriptif dengan menjabarkan hal yang terkait dengan elemen fisik yang ada dikampung. Zona dipilih berdasarkan lokasi yang sering menjadi tempat warga melakukan aktivitas berdasarkan hasil wawancara. Dibeberapa titik dilakukan wawancara untuk dapat mengetahui pola aktivitas yang sering dilakukan penduduk di zona tersebut..Elemen fisik menjadi salah satu data yang diperlukan untuk dilakukan penelitian diantaranya variable gang/jalan kecil, kios/warung, MCK umum, fasilitas sosial, lapangan dan halaman terbuka, tepi sungai. Elemen-elemen fisik tersebut mempengaruhi hakekat kampung kota yang tercipta yang disajikan dengan metode kedalam konteks yang tepat.

Dalam penelitian ini suatu perrmukiman memiliki lebih dari ruang public dari apa yang masyarakat anggap sebagai ranah publik, sehingga ruang publik dapat mempengaruhi sense of community (Talen, 2000). Untuk mengetahui karakteristik kegiatan di ruang publik terdapat beberapa indikator yang dapat digunakan intensitas penggunaan dalam kelompok,durasi aktivitas, variasi penggunaan, dan keberagaman pengguna (Mehta,2007). Penelitian juga menggunakan metode eksplanasi kualitatif yang dilakukan dengan mendeskripsikan fenomena yang ada dengan detail, juga dilakukan catatan wawancara dan melakukan analisis dokumen.

\section{HASIL DAN PEMBAHASAN}

Hakekat kampung kota dan ruang dalam arsitektur. Peran kampung tersebut akan dilihat 
dari dua dimensi realitas kampung yang tak terpisahkan satu sama lainnya, yakni:

1. Hakekat kampung tentang salah satu bentuk perumahan-kota.

2. Kampung sebagai salah satu cara hidup (way of life) dalam kota.

Secara arsitektural tata nilai kekerabatan ini berkaitan dengan konsep batas dan teritori, kedekatan tempat tinggal (spatial proximity), ruang komunal, serta pola topologis.

Kota bukanlah lingkungan binaan yang dibangun dalam waktu singkat, tetapi dibentuk dalam waktu yang panjang dan merupakan akumulasi setiap tahap perkembangan sebelumnya. Setiap lapis tahapan tersebut merupakan keputusan banyak pihak dan dipengaruhi oleh berbagai macam faktor (Alvares, 2002).

Kota pada dasarnya mampu menciptakan keunikan atau ciri khas seperti pusat bisnis, budaya, seni, ataupun ilmu pengetahuan dan teknologi (iptek), yang diolah berdasar karakter atau identitas menonjol yang sejak semula telah dimiliki. Banyak kota akhirnya menjadi masyhur, karena memang memiliki jati diri dan identitas khusus yang dimilikinya, yang dibangun dari rangkaian sejarah yang lama, dan bukan karena sekedar akibat merek tempelan yang asal dilekatkan saja di belakang nama kota sebagai semacam sebuah slogan kosong belaka, dimana bahkan untuk itu tak terdapat partisipasi warga kotanya (Abiyoso, 2007).

Beberapa kota terbesar dunia seperti New York, Tokyo, Paris, London dapat dikatakan telah menikmati hasil ketenaran nama mereka berkat karakter spesifik yang dimiliki sebagai identitas kotanya, serta kemampuan untuk terus memelihara dan membangunnya. Lebih lanjut Julia Winfield-Pfefferkorn (2005) dalam studinya The Branding of Cities, menyebutkan bahwa keberhasilan kota-kota dunia seperti New York, Paris, Rotterdam, dan San Francisco dalam menjual kotanya disebabkan karena mereka memiliki keunikan dalam salah sebuah fungsi kehidupan kota, seperti sejarah, kualitas ruang (termasuk infrastruktur), gaya hidup, dan budaya, dengan landasan program kerjasama yang mantap antar masyarakat dan pemerintah kotanya. Semua kota mempunyai identitas yang berbeda, baik yang positif maupun negatif. Identitas sebuah kota adalah keunikan kondisi dan karakteristik yang membedakannya dengan kota lainnya. Identitas kota adalah sebuah konsep yang kuat terhadap penciptaan citra (image) dalam pikiran seseorang yang sebelumnya tidak pernah dipahami. Apa kerisauannya dalam kampung tersebut ada artinya membawa identitas kota yang khas dan membuat kampung bisa menjadi identitas kota itu sendiri.Identitas kota sebenarnya tidak dapat dibangun tetapi terbentuk dengan sendirinya dan terbentuk dari pemahaman dan pemaknaan "image" tentang sesuatu yang ada atau pernah ada/melekat pada kota atau pengenalan obyek-obyek fisik (bangunan dan elemen fisik lain) maupun obyek non fisik (aktifitas sosial) yang yang terbentuk dari waktu ke waktu. Aspek historis dan pengenalan "image" yang diitangkap oleh warga kota menjadi penting dalam pemaknaan identitas kota atau citra kawasan.
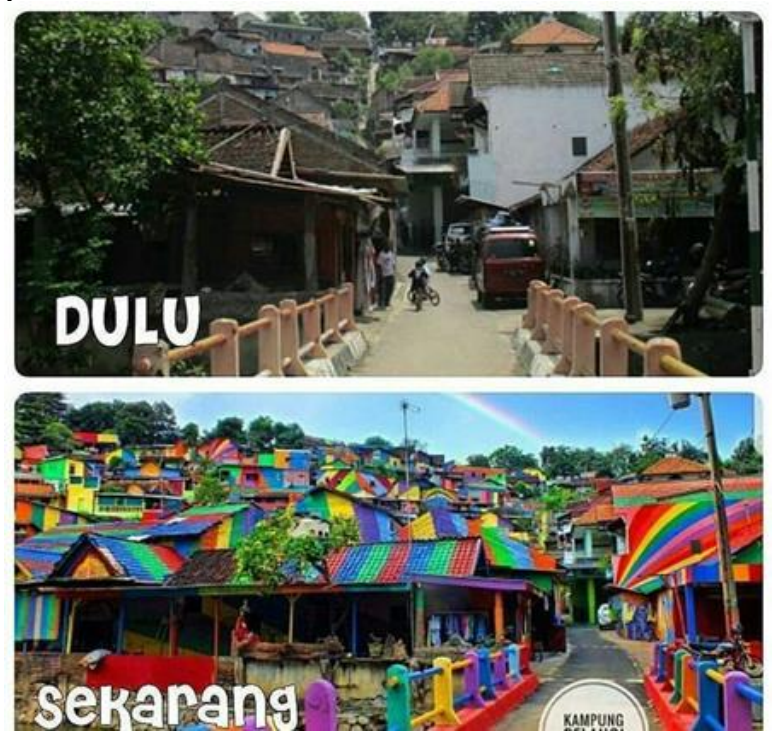

Gambar 4 Kampung Kalisari saat ini

Kampung Kalisari yang ada di Semarang ini terletak di Jalan dr. Sutomo, Kelurahan Randusari, Semarang Selatan. Tidak jauh dari Lawang Sewu. Sebelum masuk ke area kampung ini, ada Pasar Bunga Kalisari yang sudah direnovasi dan terlihat jauh lebih menarik dan tertata. Lokasi kampung ini tak jauh dari Tugu Muda dan terletak di area perbukitan sehingga terlihat dari jarak jauh

\section{Manfaat}

Analisis yang mengontekskan, mengaitkan dan menggali atau membuka seluruh aspek yang memengaruhi isu umum dalam konteks filosofis. Untuk menghindari agar kecenderungan pembangunan kampung seperti itu tidak berlanjut, perlu dipahami dan dijelaskan kondisi faktual proses perkembangan kota melalui penelusuran tatanan kehidupan kota berdasarkan apresiasi, aspirasi, kebijakan, nilai-nilai historis dan sosial 
budaya masyarakat sebagai pemaknaan identitas kota, sehingga penemuan kembali jati diri kota sebagai bagian hidup masyarakat dalam upaya pemenuhan kebutuhan warga kampung dan peningkatan kualitas lingkungannya dapat dilakukan secara berkelanjutan (sustainable) atas dasar kearifan-kearifan tradisional (indigenous knowledge). Analisis yang mengontekskan, mengaitkan dan menggali atau membuka seluruh aspek yang memengaruhi isu umum dalam konteks teori-teori arsitektur. Dengan demikian pembangunan kampung dalam kota yang diharapkan bukanlah pembangunan yang sia-sia, melainkan pembangunan kota yang dapat memenuhi kriteria pengembangan kampung dalam kota yang digambarkan oleh Bob Cowherd dalam Pekik (2003) sebagai Does The Form, Function and Meaning of the City Foster Greater Social Division or a Greater Common Good. Kaya makna (meaningfull). Ruang yang memiliki kesejarahan atau memori serta pengalaman yang berarti bagi masyarakat tertentu.

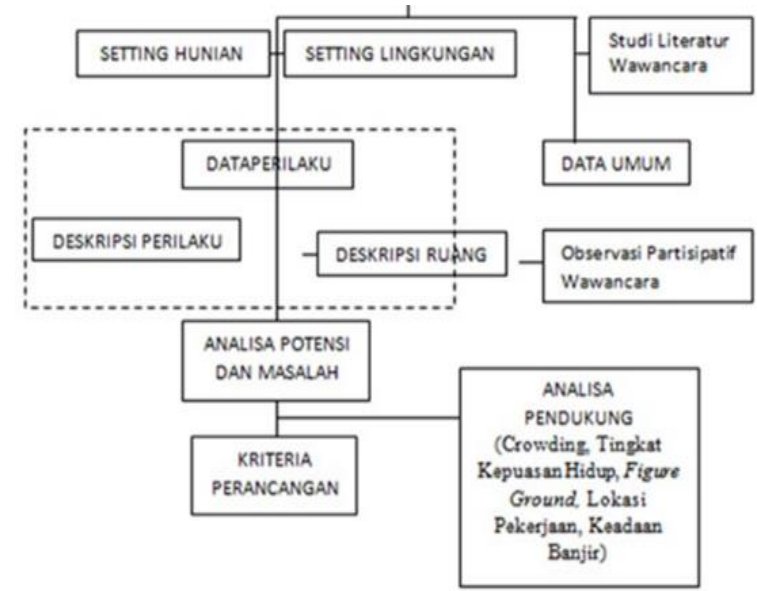

Bagan 1 Alur Pikir kajian arsitektur kampung kota

Alur pemikiran pada penelitian ini adalah kampung kota merupakan permukiman informal yang memilki karakteristik permukiman dengan kepadatan penduduk yang tinggi yang memiiliki sebuah nilai, seperti ikatan sosial dari penghuni yang dipertahankan yang terbentuk dari keragaman penghuni kampung kota tersebut. Pada dasarnya masyarakat membutuhkan ruang atau wadah beraktivitas dan berinteraksi sosial, namun pada kampung kota keberadaan ruang-ruang yang bersifat publik tersebut terbatas karena pola permukiman pada kampung kota yang tidak terencana atau informal terutama pada lingkungan dengan penduduk yang heterogen.
Kegiatan antar penghuni kampung kota mengakibatkan penghuni kampung kota memanfaatkan ruang-ruang yang bersifat publik yang tersedia ditempat tinggal mereka untuk menjadi fasilitas pertemuan antar tetangga.

Fungsi dari ruang publik tersebut adalah untuk membangun rasa kebersamaan pada penghuni kampung kota dan merupakan bagian yang penting dari terbentuknya suatu komunitas. Belum adanya penelitian secara filosofis pada kampung kota yang dapat mempengaruhi ruang dikampung kota pada penghuni menjadi persoalan. Berdasarkan hal tersebut maka pertanyaan penelitian yang akan dicari jawabannya adalah jenis ruang apa dikampung kota yang mempengaruhi penghuni kampung kota.

Untuk mencapainya hal tersebut, maka perlu mengidentifikasi jenis ruang di kampung kota dan mengidentifikasi pengukuran yang terdiri atas empat unsur, yaitu keanggotaan, pengaruh, integrasi dan pemenuhan kebutuhan, serta hubungan emosional sangat erat hubungannya dalam konteks filosofis kampung kota itu sendiri dalam penerapan kampung kota arsitektur.

\section{Penerapan kampung kota arsitektur}

Pembingkaian dengan adanya bangunan formal menyebabkan batas teritori kampung sangat jelas dan tegas sehingga makna hakekat kampung mudah dikenali. Kampung kota merupakan rumah dan bagian dari warga kota yang heterogen. Tersusun dari berbagai unsur masyarakat yang saling berbaur, saling melengkapi. Membentuk ciri dan identitas kota yang unik dan penuh warna. Selain apa yang tampak ada dibalik kampung kota bahwa yang bercampur bukan saja manusia yang berbeda-beda identitasnya. Paham-paham dan kebiasaan hidup warga kampung kota kerap kali berbenturan pun bisa hidup berdampingan di dalam kampung. Berada di antara anarki dan regulasi, dua hal yang membentuk polaritas dengan pengaruh kuat, dapat berbaur dalam satu kampung kategori slums, karena ciri-ciri fisik kampung kota yang mayoritas terlalu padat hingga mengorbankan ruang untuk fasilitas umum. Sehingga, kampung kota seringkali dikaitan dengan kemiskinan dan kriminalitas. Permukiman berwujud kampung dengan kata lain dibangun sendiri oleh warganya tanpa campur tangan pemerintah atau swasta. 
Usaha pemerintah menyediakan tempat tinggal seperti rumah susun atau perumahan jauh sangat tertinggal. Alhasil keberadaan kampungkampung pada masa modern ini masih menjadi pembentuk morfologi kota Semarang yang sesungguhnya. Bahkan pandangan kampung kota bukan lagi karena dibentuk oleh kampung tapi karena pembentukannya tidak terencana atau cenderung alamiah mengikuti kemauan sendiri. Melalui konsep ini nilai-nilai lokal tidak terkecuali kampung dapat dipertahankan sebagai daya tarik kota bukan sebaliknya menjadi obyek penggusuran.

\section{PENUTUP \\ Simpulan}

Setelah memahami beberapa permasalahan di atas, kiranya menjadi sangat penting untuk memaknai identitas sebuah kampung dalam kota, karena dengan semakin dikenalnya identitas suatu kampung dalam kota diharapkan tatanan kebutuhan hidup warganya akan semakin jelas dan terarah, serta kualitas lingkungan kampung juga dapat terpelihara dengan baik dan berkelanjutan, demikian pula sebaliknya, dengan dipahaminya tingkat kebutuhan warga dan kondisi kualitas lingkungannya akan lebih mudah memaknai identitas kota tersebut. Dengan kata lain, bila identitas dari suatu kota yang akan dikembangkan tidak dipahami secara komprehensif, sudah tentu proses pembangunan dan kehidupan warga kampung dalam kota akan semakin tidak menentu, serta kondisi fisik kota akan semrawut yang mengakibatkan terjadinya degradasi kualitas lingkungannya. Oleh karena itu, pemaknaan identitas sebuah kampung dalam kota penting untuk dipahami dengan baik dan benar, agar hal-hal yang mengakibatkan ketidakjelasan orientasi fungsi kehidupan kampung dalam kota untuk memenuhi kebutuhan warga dan penurunan kualitas lingkungan kota tersebut akan dapat diantisipasi. Kampung kota di Indonesia punya karakter spasial yang unik.

Secara teknis, karakternya sangat cair dan punya batas-batas yang tidak tegas. Ruang publik, sebagai komposisi dominan, dimiliki secara kolektif dan dipakai untuk beberapa fungsi secara bersamaan. Dengan karakter ruang seperti ini, pola tenure kepemilikan privat bukanlah pola yang tepat karena akan menghilangkan irisan-irisan sosial dan kebergantungan satu sama lain, yang selama ini dipercaya menjadi energi kampung. Secara teori, ini yang belum bisa terwujud dengan kondisi peraturan perumahan saat ini, walau memakai konsep kampung vertikal. Ketika sebuah rumah/bangunan tidak bisa dikelola mandiri atau dengan modal sosial, tapi bergantung pada "services" yang dikelola dengan basis ekonomi uang, maka keberlanjutannya bisa dipastikan tidak akan panjang, apapun nama skemanya.

\section{Saran}

Kenyataan ini menyebabkan arsitektur yang terjadi di dalam konteks kampung kota pun adalah arsitektur yang tidak pernah "selesai". Kondisi ini adalah kondisi yang rapuh, karena itu kampung seharusnya dijaga tetap dalam pola kepemilikan kelompok. Ini juga menjadi bentuk intervensi negara terhadap pasar. Arsitektur tentu bisa bercerita banyak tentang estetika kampung atau ruang-ruang organik. Dengan memahami kampung kota yang kompleks, maka akan lebih mudah dalam memahami permasalahan kota metropolitan yang sebagian besar terbangun dari kampung dimasa kini dan masa yang akan datang.

\section{DAFTAR PUSTAKA}

Abdullah, W. 1992/93. Perkampungan di Perkotaan Sebagai Wujud Proses Adaptasi Sosial: Kehidupan di Perkampungan Miskin Kota Yogyakarta. Jakarta: Proyek Penelitian Pengkajian dan Pembinaan Nilai Budaya, Direktorat Sejarah dan Nilai budaya, Depdikbud.

Adriani, M.2010 "Pemetaan Potensi Ekonomi: Ekonomi Berbasis Kampung Bumen Kotgede”. Yogyakarta:Wartakampung, Yayasan Pondok Rakyat

Adhisakti, L.T., 1997. "A Study on the Conservation Planning of Yogyakarta Historictourist City Based on Urban Space Heritage Conceptio", Kyoto University.

Amos rapoport (1969). House Form and Culture. Englewood Cliffs, N.J.:Prentice Hall.

Basundoro, P.2013. Merebut Ruang Kota: Aksi Rakyat Miskin Kota Surabaya 1900-1960-an. Tangerang: Marjin Kiri.

Evers, H.D. and Korff, R., 2000. "Southeast Asian Urbanism : The Meaning and Power of Social Space”, St. Martin's Press, New York 
Frey, H., 1999. "Designing the City : Toward A More Sustainable Urban Form", E \& FN Spon, London

Hadi, KA.2009 "Penerapan Metode Penelitian Participatory Research Apraisal Dalam Penelitian Permukiman Vernakuler (Permukiman Kampung Kota)". Dalam Prosiding Seminar Nasional Penelitian Arsitektur-Metode dan Penerapannya, Seri 2, UNDIP Semarang.

Hauser, Philip M., dkk 1985 Penduduk dan Masa Depan Perkotaan. Jakarta: Yayasan Obor Indonesia.

Heryati 2008 "Kampung kota Sebagai Bagian Dari Permukiman Kota: Studi Kasus Tipologi Permukiman RW 01 RT 02 Kelurahan Limba B dan RW 04 RT 04 Kel. Biawu Kecamatan Kota Selatan Kota Gorontalo". Fakultas Teknik Universitas Negeri Gorontalo

Newberry, J. 2013 Back Door Java.: Negara, Rumah Tangga, dan Kampung di Keluarga Jawa. Jakarta: KTLV dan Yayasan Pustaka Obor Indonesia.

Nugroho, AC.2009 "Kampung Kota Sebagai Sebuah Titik Tolak Dalam Membentuk Urbanitas dan Ruang Kota Berkelanjutan", Jurnal Rekayasa, Vol.13, No.3, Desember

Salamun, dkk. 1993/94 Sosialisasi Pada Perkampungan Yang Miskin di Kota Yogyakarta. Jakarta: Proyek Penelitian Pengkajian dan Pembinaan Nilai Budaya, Direktorat Sejarah dan Nilai budaya, Depdikbud.

Setiawan, B. 2010. "Kampung Kota dan Kota Kampung: Tantangan Perencanaan Kota di Indonesia". Pidato pengukuhan Jabatan Guru Besar dalam Ilmu Perencanaan Kota UGM, tgl 28 Oktober di Yogyakarta.

Tasdyanto. 2010 "Budaya Lingkungan Hidup Komunitas Kota di Yogyakarta". Jurnal Ekosains/Vol.II/No.3/Oktober.

Yunus, HS. 2011 Manajemen Kota: Perspektif Spasial. Yogyakarta: Pustaka Pelajar.

Juwono, Sudarmawan. (2005). Prosiding Seminar Internasional Urban Conservation Universitas Trisakti dan Universitas Tokyo. In Explore of Urban Value in Historical Urban Kampung in Jakarta. Case of Kampung Kuningan. 